\title{
THE EFFECT OF SERVICE QUALITY AND CUSTOMER VALUE TO CUSTOMER SATISFACTION \\ (Case Study on Simpedes Savings Products Customer of BRI Unit Tugu Semarang)
}

\author{
Dita Septi Setiarini, Sendhang Nurseto \\ Administrasi Bisnis, Universitas Diponegoro, Indonesia \\ Email : ditasetiarini@gmail.com
}

\begin{abstract}
In the competitive situation of banks, banks as an industry engaged in services not only offer services but also products offered by the bank. Simpedes is one of the savings products offered by BRI for the village community which then extends to the urban community using the savings products. However, customers of Simpedes savings product at BRI Unit Tugu Semarang have decreased. This is due to several complaints on customer ratings on Simpedes product services. This study aims to determine the effect of service quality and customer value on customer satisfaction in customers of savings products Simpedes BRI Unit Tugu Semarang.

This type of research is explanatory research, the method of data collection using interviews, data collection tools using a questionnaire with a sample of 100 respondents, customers are saving on Simpedes savings products. The sampling technique by purposive sampling. Data were analyzed by using validity test, reliability test, coefficient of determination, simple linear regression, multiple linear regression, $T$ test, and $F$ test with the help of SPSS 16.0 program.

The results of this study can be concluded that partially these variables have a significant effect on customer satisfaction. Service Quality affects customer satisfaction with $t$ count $(7,568)>t$ table (1,9845). The value of customer influence on customer satisfaction with t count $(8,373)>t$ table $(1,9845)$. Simultaneously, the variable of service quality and customer value have an effect on customer satisfaction with result of $F$ count $(73,837)>F$ table $(3,0902)$.

Suggestions that can be given in the research is the BRI Tugu Unit need to improve the service quality by adding employees who assist customer transactions at the teller, adding facilities for space services such as chairs and drinking water and provide attractive interest rates on Simpedes savings products.

Pada situasi persaingan perbankan, bank sebagai sebuah industri yang bergerak dalam bidang jasa tidak hanya menawarkan pelayanan namun yang juga produk yang ditawarkan oleh bank tersebut. Simpedes merupakan salah satu produk tabungan yang ditawarkan oleh BRI untuk masyarakat desa yang kemudian meluas hingga masyarakat kota yang menggunakan produk tabungan tersebut. Namun nasabah produk tabungan Simpedes pada BRI Unit Tugu Semarang mengalami penurunan. Hal ini dikarenakan beberapa keluhan atas penilaian nasabah pada layanan produk Simpedes. Penelitian ini bertujuan untuk mengetahui pengaruh kualitas pelayanan dan nilai nasabah terhadap kepuasan nasabah pada nasabah produk tabungan Simpedes BRI Unit Tugu Semarang.

Tipe penelitian yang digunakan bersifat explanatory research, metode pengumpulan data menggunakan wawancara, alat pengumpulan data menggunakan kuesioner dengan sampel 100 responden yaitu nasabah yang menabung pada produk tabungan Simpedes. Teknik pengambilan sampel dengan cara purposive sampling. Data dianalisa dengan menggunakan uji validitas, uji reliabilitas, koefisien determinasi, regresi linier sederhana, regresi linier berganda, uji T, dan uji F dengan bantuan program SPSS 16.0.

Hasil penelitian dapat disimpulkan bahwa secara parsial variabel-variabel tersebut berpengaruh signifikan terhadap kepuasan nasabah. Kualitas Pelayanan berpengaruh terhadap kepuasan nasabah dengan $\mathrm{t}$ hitung sebesar $(7,568)>\mathrm{t}$ tabel $(1,9845)$. Nilai nasabah berpengaruh terhadap terhadap kepuasan nasabah dengan $t$ hitung sebesar $(8,373)>\mathrm{t}$ tabel $(1,9845)$. Secara simultan, variabel kualitas pelayanan dan nilai nasabah berpengaruh terhadap kepuasan nasabah dengan hasil $\mathrm{F}$ hitung $(73,837)>\mathrm{F}$ tabel (3,0902).

Saran yang dapat diberikan dalam penelitian adalah pihak BRI Unit Tugu perlu meningkatkan kualitas pelayanan dengan menambah karyawan yang membantu transaksi nasabah pada bagian teller, menambahkan fasilitas untuk ruang pelayanan seperti kursi dan air minum serta memberikan suku bunga yang menarik pada produk tabungan Simpedes.
\end{abstract}

Keywords

Service Quality, Customer Value, Customer Satisfaction

Kualitas Pelayanan, Nilai Pelanggan, Kepuasan Pelanggan 


\section{Pendahuluan}

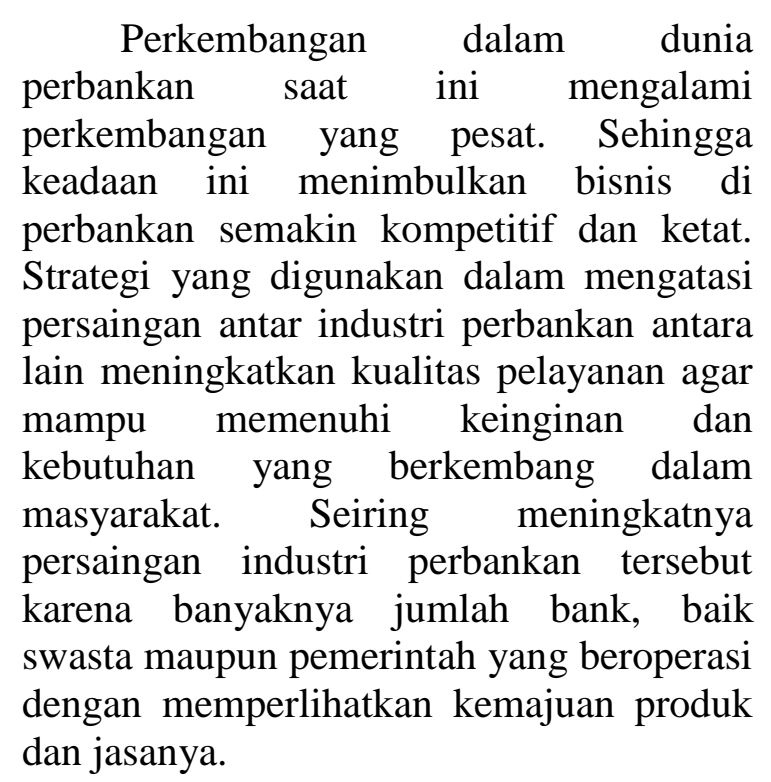

Dalam sebuah industri yang bergerak dalam bidang jasa perbankan tidak hanya menawarkan pelayanan namun yang utama adalah produk yang ditawarkan oleh bank tersebut. Produk adalah segala sesuatu yang dapat ditawarkan kepasar untuk mendapatkan perhatian, dibeli, dipergunakan atau dikonsumsi dan yang dapat memuaskan keinginan atau kebutuhan (Daryanto,2013:52).Produk yang diinginkan nasabah adalah produk yang bernilai, artinya produk yang ditawarkan oleh bank kepada nasabahnya memiliki kualitas yang lebih baik dibandingkan dengan produk bank pesaing. Bank Rakyat Indonesia saat ini memiliki beberapa produk unggulan salah satunya adalah produk Simpedes yang ditawarkan kepada masyarakat desa namun seiring waktu produk Simpedes tersebut telah digunakan oleh masyarakat kotasampai sekarang.

Dalam menentukan tingkat kepuasan, seorang pelanggan sering kali melihat dari nilai lebih suatu produk maupun kinerja pelayanan yang diterima dari suatu proses pembelian produk (jasa) (Sunyoto,2015:290)..Pada Bank Rakyat Indonesia telah berusaha untuk memberikan pelayanan yang terbaik dan juga produk yang unggul untuk nasabahnya.

Jumlah nasabah produk tabungan Simpedes mengalami fluktuatif dan target penjualan yang tidak terpenuhi. Penjualan setiap tahunnya dalam 5 tahun hanya pada tahun 2012 yang dapat melampui target yang telah ditetapkan. Dari jumlah pencapaian nasabah tabungan Simpedes, terjadi penurunan pada tahun 2015. Berdasarkan uraian di atas penulis tertarik untuk melakukan penelitian dengan judul "Pengaruh Kualitas Pelayanan dan Nilai Nasabah terhadap Kepuasan Nasabah (Studi Kasus pada Nasabah Produk Tabungan Simpedes BRI Unit Tugu Semarang)"

Berdasarkan latar belakang diatas, maka rumusan masalah yang berkaitan dengan penelitian ini adalah :

1. Apakah ada pengaruh antara Kualitas Pelayananterhadap Kepuasan Nasabah Tabungan Simpedesdi Bank Rakyat Indonesia UnitTugu Semarang?

2. Apakah ada pengaruh antara Nilai Nasabah terhadap Kepuasan Nasabah Tabungan Simpedes di Bank Rakyat Indonesia Unit Tugu Semarang?

3. Apakah ada pengaruh bersama antara Kualitas Pelayanandan Nilai Nasabah terhadap Kepuasan terhadap Nasabah Tabungan Simpedes di Bank Rakyat Indonesia Unit Tugu Semarang?

\section{Kajian Teori}

\section{Kualitas Pelayanan}

Pengertian Kualitas Pelayanan adalah upaya pemenuhan produk/jasa yang dibarengi dengan keinginan konsumen serta ketepatan cara penyampaiannya agar dapat memenuhi harapan dan kepuasan pelanggan tersebut (Tjiptono,2007:71)

\section{Nilai Nasabah}

Nilai pelanggan merupakan keseluruhan penilaian pelanggan tentang 
kegunaan suatu produk yang berdasarkan pada persepsi tentang apa yang diterima da dari apa yang diberikan (Zeithaml,1987) dalam Tjiptono(2005:145).

\section{Kepuasan Nasabah}

Kepuasan Nasabah adalah perasaan yang timbul setelah mengevaluasi pengalaman pemakaian produk. (Cadotte, Woodruff\& Jenkins, 1987) dalam Tjiptono (2016:207)

\section{Metodologi Penelitian}

Tipe penelitian yang digunakan dalam penelitian ini adalah merupakan tipe penelitian explanatory research. Metode pengumpulan data dalam penelitian ini menggunakan metode kuesioner dan wawancara dengan instrumen pengumpulan data berupa kuesioner. Skala pengukuran yang digunakan dalam penelitian ini adalah skala likert atau likert scale. Populasi dalam penelitian ini adalah seluruh nasabah produk tabungan Simpedes dan bersedia di wawancarai dan mengsisi kuesioner. Jumlah sampel dalam penelitian ini adalah 100 nasabah produk tabungan Simpedes. Teknik pengambilan sampel yang digunakan adalah non probability sampling dengan teknik purposive sampling.

\section{Teknik Analisis Data}

\section{Analisis Data Kualitatif}

Yaitu suatu analisis data yang
digunakan untuk membahas dan
menjelaskan data yang diperoleh dari hasil
penelitian tentang gejala - gejala atau kasus
yang dapat diuraikan dengan mengunakan
keterangan-keterangan yang tidak
berbentuk angka.

\section{Analisis Data Kuantitatif}

Yaitu suatu analisis yang digunakan untuk menguji hubungan antara variabelvariabel dalam penelitian dengan menggunakan perhitungan -perhitungan atau uji statistik dari data yang diperoleh yang berasal dari jawaban kuesioner dan data primer.

\section{Uji Validitas}

Uji validitas digunakan untuk mengukur sah atau valid tidaknya suatu kuesioner (Ghozali, 2005:45).

\section{Uji Reliabilitas}

Reliabilitas adalah indeks yang menunjukkan sejauh mana suatu alat pengukur dapat dipercaya atau dapat diandalkan (Sugiyono, 2009:130). Pada uji reliabilitas ini, $\alpha$ dinilai reliabel jika lebih besar dari 0,6 (Ghozali, 2005: 129).

\section{Analisis Tabulasi Silang}

Menurut Imam Ghozali (2005 : 21), analisis ini pada prinsipnya menyajikan data dalam bentuk tabulasi yang meliputi baris dan kolom. Analisis ini digunakan untuk mengetahui presentase kecenderungan antara variabel independen terhadap variabel dependen.

\section{Koefisien Determinasi}

Mengukur seberapa jauh kemampuan model dalam menerangkan variasi variabel dependen. Peneliti menggunakan nilai Adjusted $R$ Square pada saat mengevaluasi mana model regresi yang terbaik.

\section{Analisis Regresi Sederhana}

Untuk mengetahui pengaruh langsung masing-masing variabel bebas (Kualitas Pelayanan dan Nilai Nasabah) terhadap variabel terikat (Kepuasan Nasabah).

\section{Analisa Regresi Berganda}

Untuk mengetahui pengaruh (Kualitas Pelayanan dan Nilai Nasabah) secara bersama-sama terhadap variabel terikat (Kepuasan Nasabah), maka digunakan analisis regresi linear berganda. 


\section{Uji T}

Uji t digunakan untuk menunjukkan seberapa jauh pengaruh satu variabel independen secara individual dalam menerangkan variasi variabel dependen. Ini berarti uji $t$ digunakan untuk menguji signifikansi hubungan antar variabel independen (Ghozali, 2005: 30).

\section{Uji F}

Uji $F$ pada dasarnya menunjukkan semua variabel bebas yang dimasukkan dalam model regresi mempunyai pengaruh secara bersama-sama terhadap variabel terikat (Ghozali, 2005: 44).

\section{Hasil}

Penelitian ini bertujuan untuk mencari jawaban terhadap rumusan masalah yang telah dikemukakan pada bagian sebelumnya, dimana pada intinya adalah untuk mengetahui pengaruh kualitas pelayanan dan nilai nasabah terhadap kepuasan nasabah, yaitu kualitas pelayanan mempunyai pengaruh positif signifikan terhadap kepuasan nasabah. Tingkat keeratan hubungan antara variabel kualitas pelayanan $\left(\mathrm{X}_{1}\right)$ dan variabel kepuasan nasabah (Y)adalah sebesar 0,607 sehingga mempunyai arti bahwa hubungan kualitas pelayanan dan kepuasan nasabah menurut Sugiyono pada kategori kuat dan searah karena koefisien korelasinya bernilai positif. Kemudian dilihat dari uji signifikansi, yang menunjukkan bahwa nilai t-hitung sebesar 7,568 yang lebih besar dari nilai t-tabel sebesar 1,9845. Sehingga hipotesis pertama yang berbunyi "Terdapat pengaruh yang signifikan pada variabel kualitas pelyanan terhadap kepuasan nasabah pada BRI Unit Tugu Semarang" diterima.

\section{Pembahasan}

Dalam penelitian ini, kualitas pelayanan dijelaskan dengan indikator dimensi kehandalan, dimensi ketanggapan, dimensi jaminan, dimensi empati, dan dimensi tangible. Pada indikator dimensi tangible memiliki nilai rata-rata terendah, dari 6 pernyataan, pada pernyataan mengenai kelengkapan fasilitas pelayanan memiliki nilai terendah yaitu 2,51. Dari perhitungan rata-rata pada variabel kualitas pelayanan tersebut dapat dilihat item pernyataan yang memiliki rata-rata tertinggi yaitu dari indikator dimensi ketanggapan dengan mean indikator 4,77 pada item pertanyaan nomor 4 mengenai kesedian karyawan membantu nasabah.

Nilai Nasabah mempunyai pengaruh positif signifikan terhadap kepuasan nasabah. Hasil uji tersebut diperkuat dengan hasil perhitungan koefisien determinasi yaitu $41,1 \%$. Tingkat keeratan hubungan antara variabel nilai nasabah $\left(\mathrm{X}_{2}\right)$ dan variabel kepuasan nasabah (Y) adalah sebesar 0,646 sehingga mempunyai arti bahwa hubungan nilai nasabah dan kepuasan nasabah menurut Sugiyono pada kategori kuat dan searah karena koefisien korelasinya bernilai positif. Kemudian dilihat dari uji signifikansi, yang menunjukkan bahwa nilai t-hitung sebesar 8,373 yang lebih besar dari nilai t-tabel sebesar 1,9845. Sehingga hipotesis keduayang berbunyi "Terdapat pengaruh yang signifikan pada variabel nilai nasabah terhadap kepuasan nasabah pada BRI Unit Tugu Semarang" diterima.

Dalam penelitian ini, nilai nasabah indikator suku bunga yang ditawarkan Simpedes memiliki nilai rata-rata terendah, dari 5 pernyataan lainnya yaitu 3,32. Pada indikator mengenai pernyataan keamanan menabung pada nomor 21 memiliki nilai rata-rata tertinggi 4,40. Hal tersebut dikarenakan responden beranggapan bahwa bank adalah tempat paling aman untuk menabung.

Terdapat pengaruh yang signifikan antara kualitas pelayanan dan nilai nasabah terhadap kepuasan nasabah. Hasil uji tersebut diperkuat dengan hasil perhitungan koefisien determinasi yaitu $59,5 \%$ artinya variabel kepuasan nasabah dapat dijelaskan 
oleh variabel kualitas pelayanan dan nilai nasabah sebesar 59,5\%. Tingkat keeratan hubungan antara variabel kualitas pelayanan $\left(\mathrm{X}_{1}\right)$ dan nilai nasabah $\left(\mathrm{X}_{2}\right)$ dan variabel kepuasan nasabah (Y)adalah sebesar 0,777 sehingga mempunyai arti bahwa hubungan kualitas pelayanan dan nilai nasabah terhadap kepuasan nasabah menurut pada kategori kuat dan searah karena koefisien korelasinya bernilai positif. Kemudian dilihat dari uji signifikansi, yang menunjukkan bahwa nilai f-hitung sebesar 73,387 yang lebih besar dari nilai f-tabel sebesar 3,0902. Sehingga hipotesis ketiga yang berbunyi "Terdapat pengaruh yang signifikan pada variabel kualitas pelayaann dan nilai nasabah terhadap kepuasan nasabah pada BRI Unit Tugu Semarang” diterima.

\section{Kesimpulan dan Saran}

Pada bab ini disajikan kesimpulan dan saran dari penelitian mengenai pengaruh kualitas pelayanan dan nilai nasabah terhadap kepuasan nasabah pada BRI Unit Tugu Semarang beserta saransaran yang diharapkan dapat memberikan masukan dan manfaat bagi pihak-pihak yang berkepentingan.

\section{Kesimpulan}

Berdasarkan hasil dan pembahasan yang telah ditulis dalam bab sebelumnya dapat ditarik kesimpulan sebagai berikut:

1. Berdasarkan hasil penelitian menunjukkan bahwa kualitas pelayanan memiliki pengaruh positif dan signifikan terhadap kepuasan nasabah. Hal tersebut ditunjukkan dengan besarnya koefisien determinasi, bahwa pengaruh variabel kualitas pelayanan terhadap kepuasan nasabah sebesar 36,2\% serta melalui hasil uji regresi linear dimana $t$ hitung 7,568 $>\mathrm{t}$ tabel $(1,9845)$ yang berarti terdapat pengaruh positif dan yang signifikan antara variabel kualitas pelayanan terhadap kepuasan nasabah.
2. Berdasarkan hasil penelitian menunjukkan bahwa nilai nasabah memiliki pengaruh positif dan signifikan terhadap kepuasan nasabah. Hal tersebut ditunjukkan dengan besarnya koefisien determinasi, bahwa pengaruh variabel nilai nasabah terhadap kepuasan nasabah sebesar $41,1 \%$ serta melalui hasil uji regresi linear dimana $\mathrm{t}$ hitung $8,373>\mathrm{t}$ tabel $(1,9845)$ yang berarti terdapat pengaruh positif dan yang signifikan antara variabel nilai nasabah terhadap kepuasan nasabah.

3. Berdasarkan hasil penelitian menunjukkan bahwa secara bersamasama kualitas pelayanan dan nilai nasabah memiliki pengaruh positif dan signifikan terhadap kepuasan nasabah . Hal tersebut ditunjukkan dengan besarnya koefisien determinasi variabel kualitas pelayanan dan nilai nasabah terhadap kepuasan nasabah sebesar $59,5 \%$ serta dengan uji statistik $F$ yang menunjukkan $\mathrm{F}$ hitung $(73,837)>\mathrm{f}$ tabel $(3,0902)$ maka dapat disimpulkan bahwa variabel kualitas pelayanan dan variabel nilai nasabah secara bersamasama berpengaruh terhadap variabel kepuasan nasabah.

\section{Saran}

Berdasarkan kesimpulan diatas, maka peneliti mengemukakan beberapa saran yang kiranya dapat bermanfat bagi PT Bank Rakyat Indonesia, diantaranya adalah:

1. Pihak Bank BRI hendaknya mempertahankan hasil yang telah dicapai dan lebih meningkatkan mutu pelayanan kepada nasabah, meskipun kualitas pelayanan sudah baik, akan tetapi masih terdapat nasabah yang menganggap pelayanan Bank BRI kurang baik Usaha yang dapat dilakukan BRI untuk memenuhi harapan nasabah adalah dengan menyediakan fasilitas penunjang pelayanan. Salah satu yang dapat 
dilakukan oleh bank adalah sebaiknya BRI Unit Tugu Semarang memperbaiki fasilitas sistem parkir yang dianggap kurang lengkap dikarenakan belum adanya nomor parkir untuk jaminan keamanan. Sedangkan untuk ruang tunggu juga perlu ditambah misalnya dengan menyediakan televisi untuk hiburan nasabah dan menambah tempat duduk karena masih ada nasabah yang berdiri pada saat mengantri. Selain itu untuk mempercepat proses transaksi maka jumlah karyawan harus sebanding atau disesuaikan dengan jumlah nasabah

2. Pada indikator undian berhadiah yang ditawarkan oleh BRI sebagian responden menyatakan menarik, namun masih ada responden yang merasa kurang beruntung menyatakan bahwa undian tersebut hanya diberikan kepada nasabah yang memiliki saldo dan transaksi tertinggi saja. Program undian berhadiah tersebut merupakan bentuk promosi yang mampu menarik konsumen baru. Selain itu dengan adanya program undian tersebut dengan tujuan agar nasabah berlombalomba untuk meningkatkan saldo. Sebaiknya BRI memberikan program undian yang menarik untuk nasabah Simpedes khususnya masyarakat menengah bawah walaupun dengan saldo yang rendah.Bank merupakan salah satu lembaga yang dipercaya untuk menjamin keamanan atas penyimpanan dana masayarakat. Sebagian besar responden yang beranggapan bahwa jaminana keamanan pada tabungan Simpedes sudah baik. Sebaiknya kepercayaan nasabah tersebut perlu dipertahankan oleh BRI agar nasabah percaya dan tetap menggunakan produk tabungan Simpedes.

\section{Daftar Referensi}

Abdullah,Thamrin dan Francis Tantri.2014. Manajemen Pemasaran. Jakarta: PT Raja Grafindo Persada.
Aritonang, Lerbin 2005. Kepuasan Pelanggan: Pengukuran dan Penganalisisan dengan SPSS. Jakarta : PT Gramedia Pustaka Utama.

Assauri, Sofjan.2013.Strategic Marketing : Sustaining Lifetime Costumer Value.Jakarta: Rajawali Pers.

Daryanto dan Ismanto.2013. Manajemen Pemasaran. Bandung: PT Sarana Tutorial Nurani Sejahtera.

Ghozali. 2005. Aplikasi Analisis Multivariate dengan Program SPSS. Semarang : Badan Penerbit Universitas Diponegoro.

Hamidi.2005. Metode Penelitian Kualitatif. Malang:UMM Press.

Hasan,Ali. 2002. Metodologi Penelitian \& Aplikasinya. Jakarta: Ghalia Indonesia.

.2009.Marketing. Jakarta:Media Pressindo.

.2010. Marketing Bank Syariah.Bogor: Ghalia Indonesia.

Ikatan Bankir Indonesia (IBI). 2014. Memahami Bisnis Bank. Jakarta: PT Gramedia Pustaka Utama.

Ismail.2010. Manajemen Perbankan:Dari Teori Menuju Aplikasi. Jakarta: Kencana.

Isnandi, Didik. 2005. Analisis Pengaruh Customer Relationship Marketing Terhadap Nilai Nasabah dan Keungulan Produk Dalam Meningkatkan Kepuasan dan Loyalitas Nasabah. Thesis. Universitas Diponegoro.

Kasmir.2003. Manajemen Perbankan . Jakarta: PT Raja Grafindo Persada.

Kotler,Philip dan Garry Amstrong.2001. Prinsip-prinsip Pemasaran. Jakarta:Erlangga.

Kotler,Philip.2003.Manajemen Pemasaran: Analisis, 
Perencanaan,Implementasi dan Pengendalian . Jakarta:Indeks.

Kotler, Philip dan Lane Keller.2006. Manajemen Pemasaran. Edisi ke 12. Jakarta:Indeks.

Kotler, Philip. 2008. Prinsip-Prinsip Pemasaran. Buku Kedua. Edisi ke 12. Jakarta ; PT. Indeks.

Laksana, Fajar.2008. Manajemen Pemasaran:Pendekatan

Praktis.Yogyakarta:Graha Ilmu

Lailia, Nimas.2012. Pengaruh Kualitas Pelayanan, Harga Dan Nilai Pelanggan Terhadap Kepuasan Pelanggan Pengguna Jasa Servis Bengkel Ahass 0002 Semarang Honda Center. Skripsi. Universitas Diponegoro.

Lovelock,Christopher.2005. Manajemen Pemasaran Jasa. Jakarta:Indeks

Lupiyoadi, Hamdani.2006. Manajemen Pemasaran Jasa. Edisi Kedua. Jakarta:Salemba Empat

Lupiyoadi, Rambat. 2013. Manajemen Pemasaran Jasa : Berbasis Kompetensi. Jakarta : Salemba Empat

Mukarom, Moch Syaepul. 2012. Analisis Pengaruh Nilai Nasabah dan Kualitas Pelayanan Terhadap Kepuasan Nasabah Untuk Menciptakan Loyalitas Nasabah. Skripsi. Universitas Diponegoro

Oentoro, Deliyanti. 2012. Manajemen Pemasaran Modern. Yogyakarta: Laksbang Pressindo

Pontoh, Michael B. 2014. Kualitas Layanan, Citra Perusahaan Dan Kepercayaan Pengaruhnya Terhadap Kepuasan Nasabah Bank Bri Cabang Manado. Jurnal Emba, ISSN 2303-1174, Vol.2 No.3 September 2014, , Diakses tanggal 17 Juni 2016. Hal 285297.
Sipahutar, Mangasa A. 2002. Customer Focus Industri Perbankan. Bandung: CV.Alfabeta.

Singarimbun, Masri, Sofian Effendi. 1989.Metode Penelitian Survey. Jakarta: LP3AES.

Sugiyono. 2010. Metode Penelitian Bisnis. Bandung : Alfabeta.

Sunyoto, Danang dan Fathonah Eka.2015. Manajemen Pemasaran Jasa. Yogyakarta: PT Buku Seru.

Syahputra, Romachaesaria Edo.2010. Pengaruh Kualitas Pelayanan dan Kualitas Produk Tabungan Simpedes Terhadap Kepuasan Nasabah. Skripsi. Universitas Diponegoro.

Tjiptono, Fandy dab Gregorius Chandra. 2005.Pemasaran Strategik. Yogyakarya:Andi.

2006. Pemasaran Jasa. Malang: Banyu Media

. 2007. Pemasaran Jasa Edisi Pertama: Cetakan Ketiga. Penerbit Bayumedia Publising. Malang.

2008. Service Management: Mewujudkan Layanan Prima. Yogyakarta: Andi Offset.

Tjiptono, Fandy dan Anastasia Diana. 2015. Pelanggan Puas? Tak Cukup!. Yogyakarta :Andi.

Tjiptono, Fandy dan Gregorius Chandra. 2016. Service, Quality, dan Satisfaction. Yogyakarta: Andi Offset

Data Internal Perusahan. 2016. Laporan Kinerja Bisnis PT Bank Rakyat Indonesia Unit Tugu Semarang

bri.co.id yang diakses pada Senin, 8 Agustus 2016 pada pukul 13.32 WIB. 